Acta Hispanica (2019) 24: 137-146

\title{
LA ORALIDAD COMO HORIZONTE TEMPORAL DE LA INFANCIA Y DEL HOGAR MATERNO EN LA POESÍA DE CÉSAR VALLEJO Y ATTILA JÓZSEF
}

\author{
GABRIELLA MENCZEL
}

Universidad Eötvös Loránd, Budapest

\begin{abstract}
Resumen: La nostalgia, la añoranza del regazo materno, la búsqueda constante de recuerdos de la infancia, la memoria de la vida familiar son elementos recurrentes y comunes de la obra poética del peruano César Vallejo y del húngaro Attila József. Sin embargo, además de los motivos temáticos, se encuentran muchos rasgos retórico-discursivos de sus poesías, que también aluden -siguiendo la sugerencia de Julio Ortega- a la clara división de al menos dos horizontes temporales: el del pasado añorado y el del presente desilusionado. La ponencia se propone demostrar cómo la voz oral de la infancia constituye una ruptura sintáctica del discurso, en combinación con el silencio y la mudez, para convocar la palabra materna al presente continuo a través de algunos poemas de Los heraldos negros (1918) y Trilce (1922) de César Vallejo y de Medvetánc (1934) y Nagyon fáj (1936) de Attila József.
\end{abstract}

Palabras clave: infancia, oralidad, madre, César Vallejo, Attila József

\begin{abstract}
Nostalgia, longing for maternal lap, continuous seeking for childhood memories, remembrance of family life - all are recurrent elements in both poets' work, the Peruvian César Vallejo and the Hungarian Attila József. However, besides the thematic motives, there are many rhetorical and discursive features in their poetry that allude to the division of at least two temporal horizons: the longed past and the disillusioned present. This article pretends to prove how oral voices of childhood emerge as a discursive fracture in syntax, in combination with silence and muteness, in order to evoke mother's word in the continuous present, by studying volumes of both poets: César Vallejo's Los heraldos negros (1918) and Trilce (1922), and Attila József's Medvetánc (1934) and Nagyon fáj (1936).
\end{abstract}

Keywords: Childhood, Orality, Mother, César Vallejo, Attila József

A pesar de que no dispongamos de datos referentes a ningún contacto real establecido entre los dos vates de la poesía peruana y la húngara, César Vallejo y Attila József, si ahondamos en sus trayectorias poéticas, encontramos paralelismos sorprendentes. Curiosamente, ya las coincidencias biográficas llaman la atención, que sin lugar a dudas, sirven de fuente manantial y repercuten profundamente en la creación poética de ambos. ${ }^{1}$ Pues, proceden de una familia pobre, siempre adolecían de la falta de dinero, comida, ropa, casa cómoda. El padre abandona a ambas familias, la madre se encarga de los problemas de la familia entera: ganar dinero, cuidar a los hijos. Encima la madre de

\footnotetext{
${ }^{1}$ Consúltese los escritos de los biógrafos de ambos. A modo de ejemplos, nos referimos a Julio Ortega (en Vallejo, 1993), a José Miguel Oviedo (2001), o a Merlin Forster (2011) acerca César Vallejo, y a György Tverdota (1999) acerca de Attila József.
} 
La oralidad como horizonte temporal de la infancia y del hogar materno en la poesía de César Vallejo y Attila József

ambos poetas muere relativamente pronto, así a lo largo de su vida sufren de una ausencia de amor casi insoportable. Los dos intentan recompensar esta ausencia de diferentes maneras. Buscan reconciliación en el amor de las mujeres y entran en la lucha social contra la pobreza uniéndose a los movimientos izquierdistas marxistas. Todos estos acontecimientos que les acompañan durante su vida, también se manifiestan en su poesía. La nostalgia, la añoranza del regazo materno, la búsqueda constante de recuerdos de la infancia, la memoria de la vida familiar, la orfandad, la exclusión son elementos recurrentes y comunes de la obra poética del peruano César Vallejo y del húngaro Attila József.

César Vallejo es el poeta exiliado por excelencia que tras el abandono de su hogar familiar solo volvió una vez a su pueblo natal, Santiago de Chuco y, por consiguiente, tuvo que experimentar uno de los traumas más marcados de su vida: la prisión injusta (Oviedo, 2001:327). Sin embargo, además de los motivos temáticos, se encuentran muchos rasgos retórico-discursivos de sus poesías, que también aluden -siguiendo la sugerencia de Julio Ortega- a la clara división de al menos dos horizontes temporales: el del pasado añorado y el del presente desilusionado (Ortega, 2014:97).

Attila József también fue el hijo menor de una familia pobre. Su padre también les abandona, la madre emprende trabajo en la casa de familias acomodadas: lava ropas, plancha, limpia la casa, pero no puede mantener a sus tres hijos, por eso los manda a vivir con padres adoptivos. Cuando la madre muere, a los catorce años del poeta, Attila József tiene que mantener la familia, pues, emprende trabajos ocasionales. Como en la vida de Vallejo, la muerte de su madre es un dolor insoportable lo que le es imposible traspasar. Así los temas fundamentales de su obra serán: la madre, el padre, la familia y su ausencia, Dios y el pecado (Tverdota, 1999:219-255).

En cuanto a su teoría estética, encontramos similitudes conceptuales, especialmente en lo que se concierne a la palabra poética. César Vallejo en uno de sus artículos afirma que "[el] material más elemental y simple del poema es, en último análisis, la palabra y el color de la pintura” (1929:68). Mientras en el pensamiento del húngaro Attila József, el poema lírico se concibe como una única palabra en gestación (1931:38). Sin lugar a dudas, ambos profesan el vigor mágico de la palabra, que -muy de acuerdo con el precepto vanguardista del estatus del signo poético- en vez de aludir a la realidad, pierde su referencialidad inmediata y se convierte en la realidad misma.

Partiendo de los detalles antes enumerados, no sorprende que sea la infancia un motivo temático destacado y, por consiguiente, brote la oralidad como naturaleza inherente de la poesía de estos dos poetas de dimensión universal. En esta ocasión nos proponemos demostrar cómo la voz oral de la infancia constituye una ruptura sintáctica del discurso, para convocar la palabra materna al presente continuo a través de dos poemas de Trilce 
(1922), los que llevan el número tres y el veintitrés, y dos de la última época de Attila József ("Mamá" de Medvetánc, 1934, y "Llanto tardío" de Nagyon fáj, 1935). Por supuesto, el tema es muy amplio con muchos matices, aquí nada más pretendemos enfocarnos en estos poemas en concreto, lo que no significa que no encontremos muchos otros puntos en común o motivos para comparar. (Por ejemplo, el color azul. Vallejo en Trilce VI (poema aquí no comentado) denomina a la figura ausente "mi lavandera" que al final del poema "puede [...] / azular y planchar todos los caos", 1993:63, como Attila József en "Mamá", quien "echa su añil en el agua del cielo", 1999:42 $)^{2}$.

Para Julio Ortega, en la poética de Vallejo, la enunciación coloquial desarrolla la temporalidad, en el sentido de que la oralidad constituye el ámbito de la duración (Ortega, 2014:140). El lenguaje oral del habla cotidiana emerge como materialidad lingüística, es el sesgo físico, corporal del hablante, presente en toda la poesía de César Vallejo desde Los heraldos negros (1918) hasta sus últimos Poemas bumanos (1939). Sin embargo, hay una notable diferencia entre el sujeto del coloquio inicial y el del final de su trayectoria. En Los heraldos negros y también en algunas piezas de Trilce el sujeto del coloquio, recobra evidentemente la voz de la infancia, y pone en manifiesto la ausencia de respuestas, la carencia de interlocutor inmediato. Diríjase a Dios, a la madre o bien, a la amada perdida, ninguno le devuelve la respuesta (Ortega, 2014:140). (En cambio, en Poemas humanos y en España, aparta de mí este cáliz, reconocemos la presencia de una serie de interlocutores [el miliciano muerto, el obrero, los compañeros, los niños], por lo tanto, salta a la vista el carácter dialógico, su adhesión a normas regionales, a un léxico peruano.)

El título de Trilce en sí ya tiene que ver con la oralidad, con el balbuceo que determina el principio creador del libro. La anécdota se conoce bien del testimonio directo de Juan Espejo Asturrizaga, biógrafo importante de Vallejo quien recuerda que el hecho de que Vallejo tuviera que pagar tres libras extras con el fin de cambiar su seudónimo -César Perú- en su apellido real y así tirar de nuevo las primeras páginas, le preocupó tanto que volvió a repetir las palabras "tres libras" deformándolas, de las que al final salió "trilce" (citado por Ortega, en Vallejo, 1993:25).

La tercera pieza de Trilce y "Mamá" pueden verse como ejemplos paradigmáticos de esta dualidad de voces. Teonilda Madera entiende el poema de Vallejo como la reconstrucción de la infancia desde la postura del niño atemorizado (2008:10). En la primera estrofa se escucha la voz infantil miedosa por el abandono de los mayores y de la oscuridad de la noche ("Las personas mayores/ ¿a qué hora volverán? / Da las seis el

\footnotetext{
${ }^{2}$ Citamos los versos de Attila József en la traducción de Fayad Jamís de los años sesenta (1999).
} 
La oralidad como horizonte temporal de la infancia y del hogar materno en la poesía de César Vallejo y Attila József

ciego Santiago, / y ya está muy oscuro.”), y se mezcla con la esperanza de la reaparición pronta de la madre ("Madre dijo que no demoraría.")

En este tercer poema de Trilce se representa muy claramente la división entre los horizontes temporales presente y pasado. El lenguaje infantil del inicio que adopta y reproduce las fórmulas y las instrucciones repetidas de los adultos ("Vamos viendo/ los barcos jel mío es más bonito de todos!" / con los cuales jugamos todo el santo día, / sin pelearnos, como debe de ser”) (Vallejo, 1993:51; Escobar, 1973:99-100), o bien, al final en los vocativos de la última estrofa, cercanos al coloquio oral de los niños ("Aguedita, Nativa, Miguel?", 52), gradualmente cambian no de sujeto, pero sí de horizonte temporal: el último verso aclara la postura del yo del presente ("y el único recluso sea yo"), que para Américo Ferrari indica que el poema fue escrito en la cárcel (citado por Ortega, en Vallejo, 1993:54). Los dos penúltimos versos representan la transición sutil de un plano al otro, ya que perfectamente corresponden tanto al juego infantil al escondite como a la condición solitaria, encerrada del yo adulto ("Llamo, busco al tanteo en la oscuridad. / No me vayan a haber dejado solo", Vallejo, 1993:52). El uso del pretérito, o sea del infinitivo compuesto también señala la postura del sujeto de filtrarlo todo a través de la memoria. No en vano, las últimas tres palabras marcadamente posicionadas al final de los versos ("oscuridad", "solo", “yo") subrayan la condición del aislamiento, de tanteo, de privación de la vista, de soledad del sujeto hablante. Esta última angustia del ser reaparece en otros poemas del libro, como, por ejemplo, en el XVIII, donde la cárcel se convierte directamente en la condición irresoluble de desamparo del ser humano ("esta mayoría inválida de hombre", Vallejo, 1993:107).

Dos poemas archiconocidos en Hungría, de los últimos dos volúmenes de Attila József, "Mamá" (József, 1999:42) y "Llanto tardío" (44-45), tematizan precisamente la figura de la madre en el mismo sentido. En esta última época, a partir de 1931 Attila József, ya está frecuentando con regularidad a sus psicoanalistas para tratar su depresión neurótica (Sárközy, 2001:49). Ambos poemas remontan al momento de la muerte irrevocable de la madre, hacia la que sentía una añoranza muy fuerte desde niño. En ambos poemas se tematizan la orfandad solitaria, el sentido de la carencia universal, donde la poesía emerge como un grito de dolor, y la palabra poética será el único y el último apoyo (Vass, 1968:449).

El vocativo oral marca la doble posición del yo lírico: en "Mamá", el sujeto del presente ("Desde hace una semana en mi mamá/ sólo pienso, abstraído; en mi mamá") enfrentado al del pasado ("deja para otro ese pesado y gran/ bulto, mi madre, y llévame al desván”, József, 1999:42). De manera un tanto distinta, en "Llanto tardío", el sujeto queda encerrado, y así bloqueado e incomunicado con el recuerdo de la madre, y el tono resignado del poema anterior aquí se vuelve claramente acusador y demandante: 


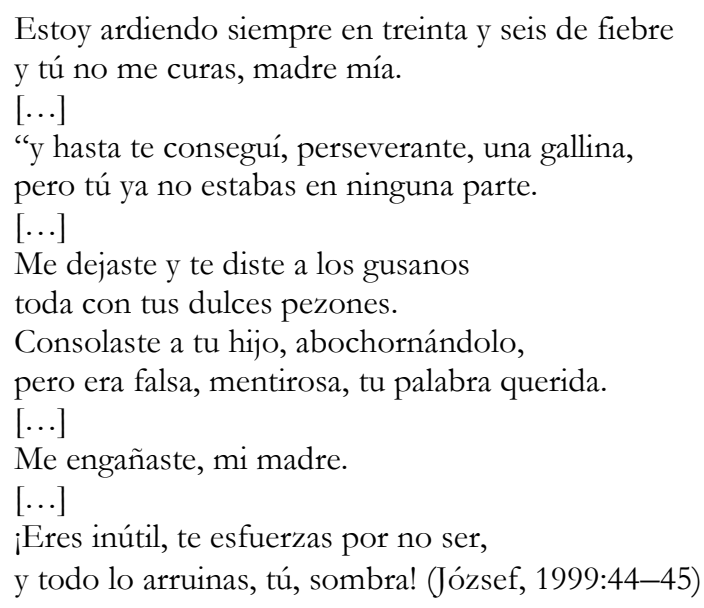

Esta diferencia entre las voces de los dos poemas de Attila József es parecida a la disimilitud entre los dos poemas de Vallejo. El paralelismo, entonces, se traza más bien entre "Mamá" y el III de Vallejo, al igual que entre este último poema de Attila József ("Llanto tardío") y el poema XXIII de Trilce. Mientras Attila József se refiere a la falta de pan, Vallejo en Trilce XXIII evoca la dualidad semántica del pan, en su sentido de alimento básico cotidiano, vinculado estrechamente con la madre, y en el sentido religioso del ritual de la hostia del sacrificio, y con a la mesa ("tahona") del hogar como centro espiritual (Vallejo, 1993:130). A los hermanos identificados como "mendigos" del amor maternal (Escobar, 1973:154), que a pesar de que en el pasado fue la "mamá" que repartía los bizcochos, se los cobrarán en el presente irremediablemente. La felicidad amorosa de la infancia se convierte así en un sentimiento de deuda culpable (Vallejo, 1993:131), mientras tanto, la madre en arquetipo eterno ("innumerable", "inacabable", 129-130), de dador de vida que nos alimenta espiritualmente en la comunión (Vallejo, 1993:133).

En el "Llanto tardío" de Attila József, en lugar de combinar los dos horizontes temporales, se citan directamente las palabras de la madre como recuerdo, también, en vinculación con el alimento ("Decías: ¡Come, creces para mí, mi santo!"), pero sin posicionarse en el pasado. Al contrario, al final del poema se distancia incluso de esta imagen rememorada de la madre, y en la última estrofa el yo lírico se torna en tercera persona, que prevé su fin irremediable: 
La oralidad como horizonte temporal de la infancia y del hogar materno en la poesía de César Vallejo y Attila József

Poco a poco amanece en mi mente, se acabó la leyenda.

El niño que pende del amor de su madre se entera al fin que es un tonto.

Quien fue parido de madre al fin se desengaña, así, o porque él mismo trata de engañar.

Si lucha, muere de su lucha, si se reconcilia, su reconciliación es su fin. (József, 1999:45)

Péter Vass, a pesar de su interpretación matizada por la ideología comprometida marxista-socialista, constata una de las claves de estos poemas que evocan la figura de la madre en dos horizontes irreconciliables. En caso de "Llanto tardío" reconoce la intencionalidad frustrada del diálogo, que denomina "pseudo-diálogo" (1968:455) que ciertamente es característica también de los poemas vallejianos mencionados.

María Ema Llorente en su estudio muy substancial y admirablemente condensado acerca de la oralidad y la génesis de sentido de la misma en Trilce, basándose en la teoría de la poesía oral de Paul Zumthor, resume en tres puntos los mecanismos de tal oralidad en la poesía de Vallejo, que sin duda, van en busca de la liberación de las imposiciones de la escritura, y de una alternativa a la comunicación del sentido "desde los márgenes del logocentrismo", con el término de Julio Ortega (citado por Llorente, 2005:107). La primera característica es la naturaleza de los textos como borradores, es decir la imperfección general o falta de elaboración de los textos orales, que parecen estar en proceso, la distribución fragmentaria que invita a autocorregirse (Llorente, 2005:108). La corrección, sin embargo, no significa aquí tachar o borrar algo y sustituirlo por otra versión, sino conservar todas las variantes, todos los titubeos, en busca del sentido correspondiente.

La segunda característica de la oralidad, según Llorente, es la repetición de palabras, de sintagmas y de frases, aunque sea parcial o con variaciones que, por lo tanto, se convierte en el mecanismo fundamental de la organización de esta escritura de la oralidad, que Zumthor tildaría como "oralidad segunda" (Llorente, 2005:37) "(donde toda expresión está marcada por la presencia de lo escrito)” (Llorente, 2005:37). Mediante la construcción "en listas", por acumulación, los elementos se yuxtaponen como equivalentes, coordinados, que cumplen la misma función. "Como consecuencia, el texto se ralentiza y aunque puede perder en eficacia comunicativa, gana en intensidad y en valor poético" (Llorente, 2005:109). Este efecto se aprecia en la tercera estrofa de "Llanto tardío":

Me dejaste y te diste a los gusanos

toda, con tus dulces pezones.

Consolaste a tu hijo, abochornándolo,

pero era falsa, mentirosa, tu palabra querida. 


\section{Gabriella Menczel}

Enfriaste mi sopa removiéndola, soplándola.

Decías: ¡Come, creces para mí, mi santo!

Y ahora tu boca vacía saborea la humedad pegajosa.

Me engañaste, mi madre. (József, 1999:45)

En el fragmento citado efectivamente vemos elementos yuxtapuestos que así se comprenden como equivalentes ("me dejaste", "te diste a los gusanos", "consolaste a tu hijo", "enfriaste mi sopa", "decías", y "me engañaste”), repeticiones de sinónimos ("falsa", "mentirosa"; "removiéndola", "soplándola").

La penúltima estrofa del poema XXIII de Vallejo también abunda en elementos de esta índole:

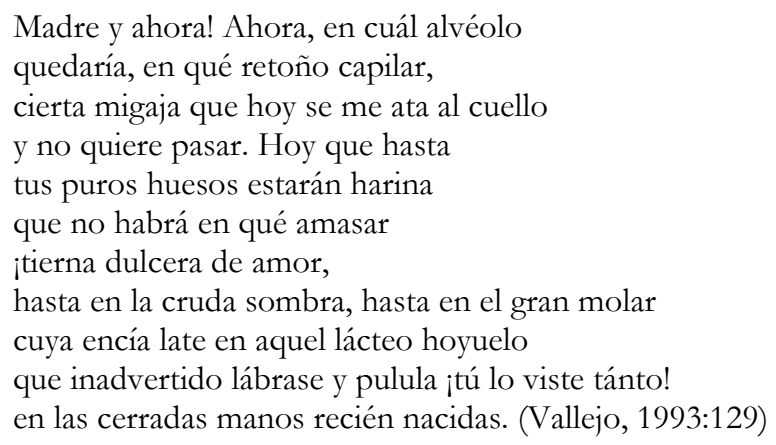

En la estrofa arriba citada se repiten incluso las mismas palabras ("ahora", "hoy"), o las estructuras sintácticas ("en cuál alvéolo", "en qué retoño"; "hasta tus puros huesos", "hasta en la cruda sombra", "hasta en el gran molar") para crear tal efecto de oralidad. La progresión de la redundancia plantea además una cuestión temporal que avanza desde la madre, desde el pasado de la infancia, hasta el presente desolado del adulto, abandonado y huérfano (Llorente, 2005:111). De tal forma, la repetición alternada o progresiva provoca, además, una construcción rítmica muy particular (Llorente, 2005:118).

Una tercera característica del discurso oral es la suspensión del sentido, que generalmente se produce acompañada por una sintaxis elíptica y extraña, que desemboca con frecuencia en una agramaticalidad comentada muchas veces por la crítica (Llorente, 2005:119). La repetición acumulativa de listas, y la agramaticalidad elíptica, estos últimos rasgos mencionados de la oralidad, también aparecen en los cuatro poemas paradigmáticos elegidos.

Si admitimos la observación de los biógrafos de ambos poetas, según la cual en la figura de la madre perdida confluyen todas las mujeres amadas, el sentimiento de la soledad 
La oralidad como horizonte temporal de la infancia y del hogar materno en la poesía de César Vallejo y Attila József

incrementa aún más. (Con respecto de Trilce, María Ema Llorente observa que la figura de la madre ausente se toma cuerpo en la figura de la amada, que necesariamente es insuficiente para evitar el dolor impulsivo e inevitable de la existencia.) "No es casual que el discurso aparezca como repetitivo o fragmentario, puesto que proviene de un hablante que se encuentra en un estado de exaltación emocional. El texto se encuentra motivado internamente por la elevada carga emotiva de su contenido y su inefabilidad o imposibilidad de expresión. Esta emoción convierte a Trilce en un grito de dolor, sentimiento que se revela como la fuerza motora de todo el libro" (Llorente, 2005:113). Lo mismo podemos observar en el caso del "Llanto tardío" de Attila József.

En Attila József, "Llanto tardío" designa el género de la endecha en el título, practicada por una comunidad de plañideras, género por excelencia oral, que institucionaliza y determina formalmente el velorio del fallecido, y que pocas veces implica emociones personales sinceras (Bókay, 2004:179). El atributo "tardío" necesariamente deconstruye la coherencia de la endecha, alude a algo que ya ha perdido su actualidad, su validez. Si el llanto, el luto no ha cumplido su función en el momento necesario, a través del acto repetido se vuelve constantemente presente, el recuerdo se convierte en una presencia imborrable (Bókay, 2004:179). La madre que ofrece alimento a su hijo, al final se entrega para nutrir a la muerte ("te diste a los gusanos", József, 1999:45). En el poema XXIII de Vallejo es la gran boca de la muerte que se identifica con la del recién nacido, aumentando así el sentimiento de culpa ("hasta en el gran molar/ cuya encía late en aquel lácteo hoyuelo", 1993:129). En ambos poemas el engaño es un motivo clave: ambas madres dieron de comer a los hijos, y se les acusa de haberlo retomado ("Lo que me diste, zalamera, / ¡todo me lo robaste a última hora!”, József, 1999:45; “Y nos lo cobran, [...] / cuando tú nos lo diste", Vallejo, 1993:130).

Los vocativos directos, los apóstrofes en ambos casos sirven de entablar el diálogo mediante la figura de la prosopopeya. Para Jonathan Culler, el apóstrofe, en un primer nivel, designa la voluntad de realizar una situación, invocar a objetos inanimados con el fin de que lleven a cabo nuestro anhelo (2000:374). Muchas veces se origina de una emoción fuerte, una pasión representada metonímicamente (2000:373). En un segundo nivel, constituye el encuentro con el mundo como una relación intersubjetiva (Culler, 2000:376). Otro paralelismo llamativo en los poemas es el cambio de la denominación, pues, en ambos casos, primero se la llama "madre" que más adelante será "mamá", o sea que se personifica la madre ausente, y de tal forma, se la invoca, y a pesar de asignar su ausencia y el dolor por esta carencia, al mismo tiempo, se la eterniza (Bókay, 2004:187). Al igual que Attila József, también César Vallejo en la última estrofa explicita el reconocimiento de la no presencia maternal ("la tierra oirá en tu silenciar", 1993:130), oxímoron en el que hasta esta ausencia se verbaliza literalmente, pues, a través de la forma verbal se subraya la naturaleza activa del estado inanimado. Sin embargo, en Vallejo, la última enunciación es el apóstrofe oral “¿di, mamá?”, una pregunta que 
reclama respuesta, que no llega, y así termina en el silencio preanunciado. Attila József realiza el mismo acto de invocación en la penúltima estrofa (“¿No lo oyes, mamá? ¡Regáñame!’), y explicita la reconciliación que irremediablemente conduce a su fin, a la muerte, al silencio ontológico. Este silencio, por una parte, también anuncia el silencio que espera al sujeto lírico, es decir, lo acerca a su propio fin, y por otra, tal y como constata Culler, en una función de tercer nivel del apóstrofe, el vocativo no es más que un medio de la voz lírica para (re)crear su propia identidad, su propia subjetividad (2000:376-377). La invocación desde su acepción arcaica presupone la capacidad de animar a objetos inanimados, a seres mitológicos, o a la naturaleza. Lo hace gracias a interpretar al objeto en su función de sujeto, como un "tú", dándole vida, y tal encarnación solo puede ocurrir por medio del acto poético (Culler, 2000:377). Por eso no sorprende, que los poemas terminen con una resignación, reconociendo el carácter ficticio (y no referencial) de la situación creada (Culler, 2000:378). Sin embargo, en lo que atañe a su temporalidad, el apóstrofe en un cuarto nivel, es signo de un presente atemporal, o mejor dicho, la temporalidad de la escritura (Culler, 2000:383). Invocar a las figuras lejanas, a los objetos inanimados, significa ubicarlos en el tiempo del apóstrofe, en el ahora de la escritura, de la poesis. Serán elementos del acontecimiento anhelado por el sujeto poético y la temporalidad referencial se sustituye por la temporalidad del discurso (Culler, 2000:383). A partir de este punto, el juego alternativo de presencia y ausencia se guía no por la oposición temporal empírica, sino por la instancia creadora, por el poder poético (Culler, 2000:384). El apóstrofe como tropo principal en estos poemas no sirve para representar el acontecimiento, sino para crearlo, llevarlo a la realidad mediante el discurso ficticio (Culler, 2000:387). La madre, a fin de cuentas, a través de invocarla con la voz "mamá" se eterniza para siempre.

Américo Ferrari, excelente lector de Vallejo, formula unas conclusiones que a nuestro juicio son más que ciertas también en el caso de Attila József, puesto que reiteran los conceptos clave de los poemas estudiados: "Se trata, en suma, de una poesía imperfecta, es decir, siempre abierta. Cada poema [de Trilce] se prolonga, por así decirlo, más allá de sí mismo, rebasa el ámbito de los pocos versos que lo constituyen, en el sentido que la obsesión que le da vida, y alimenta su forma, no llega a resolverse al fin del poema, se prolonga en el silencio, y reaparece en otro poema, tan poco "perfecto" como el precedente. El poeta busca y no encuentra, pero a cada paso de la incesante busca está forjando su lenguaje, el lenguaje más adecuado posible, el más libre y el más amplio, en la medida en que tal libertad y tal amplitud son compatibles con las limitaciones inherentes al universo de las palabras (Ferrari, 1997:282-283). ${ }^{3}$

${ }^{3}$ Los subrayados son del original. 
La oralidad como horizonte temporal de la infancia y del hogar materno en la poesía de César Vallejo y Attila József

\section{Referencias bibliográficas}

Bókay, Antal (2004). József Attila poétikái. Budapest: Gondolat.

Culler, Jonathan (2000): Aposztrophé. Trad. Széles Csongor. Helikon, 3. 370-389.

Escobar, Alberto (1973). Cómo leer a Vallejo. Lima: P.L. Villanueva Ed.

Ferrari, Américo (1997). El universo poético de César Vallejo. Lima: El Heraldo.

Forster, Merlin (2011). “Un pedazo de pan, ¿tampoco habrá ahora para mí?”: comida y sufrimiento en la poesía de César Vallejo. En: García, Mara L. 2011. César Vallejo: Estudios y panoramas críticos. Universidad Nacional de Trujillo, Perú: Instituto de Estudios Vallejianos. 51-63.

József, Attila (1999). Poesías. Trad. Fayad Jamís. Sel. y prólogo de András Simor. Budapest: Eötvös József Könyvkiadó.

József, Attila (1931). Irodalom és szocializmus. Művészetbölcseleti alapelemek. En József, Attila. Költészetés nemzet. 1989. Budapest: Bethlen Gábor Könyvkiadó. 19-44.

Llorente, María Ema (2005). Oralidad y sentido en Trilce, de César Vallejo. Revista de Humanidades: Tecnológico de Monterrey (México), 18. 105-132.

Madera, Teonilda (2008). Polifonía, corporeidad y memoria en el universo poético de César Vallejo $y$ de Blanca V arela. Tesis doctoral. The City University of New York.

Ortega, Julio (2014). César V allejo. La escritura del devenir. Barcelona: Taurus.

Oviedo, José Miguel (2001). Vallejo entre la agonía y la esperanza. En Oviedo, José

Miguel. Historia de la literatura hispanoamericana 3. Postmodernismo, Vanguardia, Regionalismo. Madrid: Alianza. 318-348.

Sárközy, Péter (2001). “Kiterítenek úgyis”. József Attila kései költészete. Budapest: Argumentum.

Tverdota, György (1999). József Attila. Budapest: Korona.

Vallejo, César (1993). Trilce. Ed. Julio Ortega. Madrid: Cátedra.

Vallejo, César (1929). La nueva poesía norteamericana. El Comercio. Lima, 30 de julio de 1929. Reproducido en Aula Vallejo 5-6-7. Universidad de Córdoba, Argentina. 1968. 68.

Vass, Péter (1968). A tartalom és a forma kérdései József Attila Kései sirató-jában. Irodalomtörténeti Közlemények, LXXII, 4. 449-455.

Zumthor, Paul (1991): Introducción a la poesía oral. Trad. M Concepción García-Lomas. Madrid: Taurus. 